\title{
Application of the Case Study Method in Medical Education
}

\author{
Oleksandr Y. Korniichuk \\ State Institution "Dnipropetrovsk Medical Academy of the Ministry of Health of \\ Ukraine", Dnipro, Ukraine \\ https://orcid.org/0000-0002-9020-8109 \\ Leonid M. Bambyzov \\ Zaporizhia State Medical University, Zaporizhia, Ukraine \\ https:/ / orcid.org/0000-0002-0501-0852 \\ Valentyna M. Kosenko \\ Zhytomyr Medical Institute of Zhytomyr Regional Council, Zhytomyr, Ukraine \\ https://orcid.org/0000-0002-4486-8317 \\ Anastasiya M. Spaska \\ Ajman University, Ajman, UAE \\ https:/ / orcid.org/0000-0002-3505-3407 \\ Yaroslav V. Tsekhmister \\ Ukrainian Medical Lyceum of Bogomolets National Medical University, Kyiv, Ukraine \\ https://orcid.org/0000-0002-7959-3691
}

\begin{abstract}
Reducing the gap between professional opportunities of graduates of medical education institutions and needs of patients is the priority of medical education. The introduction of interactive methods, in particular the case study method, can help solve this problem. The aim of this study was to investigate how the application of the case method in medical education affects the learning outcomes of students and acquisition of practical experience. Case method was used to identify its impact on the acquisition of practical skills, abilities and clinical experience by future physicians. Students' opinions on the effectiveness of the case method in gaining practical experience were surveyed. The study showed that the case method helped students find solutions required by clinical situations, as they used not only theoretical knowledge, but also acquired practical skills and clinical experience. The case method also increases students' confidence in their professional abilities. This experimental study proved the high efficiency of using the case method in medical education to gain practical experience by students in the education institution. It can be useful for scholars and educators
\end{abstract}


who are looking for, developing and implementing effective teaching methods that allow students to acquire the necessary competencies.

Keywords: teaching methods; clinical case; clinical situation; medical experience; interactive method

\section{Introduction}

An important objective of higher medical education is the development of students' skills necessary for successful future clinical practice (Skrypnyk et al., 2012). Students must be able to process information obtained from the examination of the patient, identify the main points, systematize, summarize, assess the need for additional examinations, and build a plan according to which these should be carried out. It is also necessary to teach students to analyse the obtained results of examinations and to make a diagnosis, and to prescribe an appropriate and effective treatment according to the current protocols of treatment, the diagnosis and features of a particular clinical case.

Future physicians gain experience in clinical practice while studying at a medical education institution through the use of case methods in their teaching and learning. The mistakes they may make at this stage do not entail life-threatening implications (Skrypnyk et al., 2012). These case methods can be used not only in in-class learning, but also in e-learning or distance learning (Ali et al., 2018; Turk et al., 2019).

The main purpose of the case method is to conduct a comprehensive, integrated in-depth study of a complex issue, phenomenon, event, situation, case, programme, person or group of people. This study must be conducted in a specific context (real life, authentic conditions), where the boundary between context and problem is not obvious. The situation may have many variables, because many phenomena and processes intersect in one situation or case. One of the objectives of using the case method is to increase motivation and thus achieve a deep understanding of complex processes and phenomena (Harrison et al., 2017). The case study method is considered to be the link between theory and practice in medical education (Turk et al., 2019).

The case study dates back to Harvard Law School in the 1870s (Servant-Miklos, 2019). In 1900, case methods were used in medical school, and from 1908 in business school, although, according to other scientists (Litvinova et al., 2017), the method came into use in medicine in the 1920s.

The case method quickly spread beyond Harvard (Servant-Miklos, 2019). It is currently used in the education and training of not only physicians (Chamala et al., 2021; Wei et al., 2021), but also of specialists in other professions in education institutions worldwide (Zakaliuzhnyi, 2019). The case study method currently is most commonly used in North America - $54.93 \%$ of all research papers dealt with this method. It is less popular in Europe (25.35\%), in Asia (15.49\%), in South America (2.82\%), and in Africa (less than 2\%) (McLean, 2016). 
Case studies appeared in medical schools as an alternative to lectures that were considered ineffective for practical medicine (McLean, 2016). However, the contrary opinion is that lectures are a very powerful and useful tool in teaching medical students to master the fundamental knowledge needed to solve specific problems (Tsekhmister et al., 2019; Vasylieva, 2020).

The process of formulating a case situation, that is, the path of a clinical case from a patient to medical institutions is quite complex (Sayre et al., 2017). Despite this, a great variety of cases have been classified, for example, by type and direction, structure, way of presentation, content, complexity, volume, the plot, goals and objectives of the educational process, the subject of the case, and the purposes of using the case method (Likhachov et al., 2019) . In the largest database of case studies of the European Case Clearing House $(\mathrm{ECCH})$, cases are classified as follows: case studies, auxiliary cases, exercise cases, complex cases, solutions cases.

Different scholars identify different stages of working on cases in medical education, such as: development of a clinical case, search of literature to address a clinical issue, critical evaluation, and application of the results of the study to the patient's treatment (Napryeyenko et al., 2019; Zarnadze et al., 2018). The teaching plan for using the case method is as follows: Students are given data on the actual case. The data should be analysed independently by students (diagnosis, prognosis, treatment). This is followed by a discussion of all aspects of the problem by students who should respond like professionals in the presence of a teacher. The teacher should not impose his/her opinion, but rather pose questions that may guide students' answers to their theoretical knowledge that may prompt them to find the correct solution to the problem (Servant-Miklos, 2019). Students' work on cases improves their skills and provides knowledge and the ability to apply critical and analytical thinking, and use theoretical and relevant knowledge (Edenhammar, 2017). Often the cases considered in case studies do not have a single solution, that is, they are ambiguous; therefore, it is important that teachers' questions to students during case study discussions must be enabling (Gartmeier et al., 2019).

In the learning process, cases can be used as illustrative material, to substantiate diagnostic methods (Pavlyshyn et al., 2015), as the premise for discussions, for specific questions and answers, and for a detailed cross-examination, and also in assessing student competence (Orban et al., 2017). Cases all must have a specific goal, purpose, educational procedure, and must be linked to knowledge and application (Servant-Miklos, 2019).

Scientists often compare the case method and problem-based learning (ServantMiklos, 2019). What these methods have in common is that the learning process takes place through solving life situations in a small group of students under the guidance of a teacher. Edenhammar (2017) and Eid and Quinn (2017) also compare the case method with traditional teaching methods. Combining innovative lectures with reviewing practical situations not only enhances learning outcomes (Sandelowsky et al., 2018), but also provides knowledge necessary for independent work of physicians, to understand the causes of specific situations, 
and make appropriate and effective decisions (Edenhammar, 2017). In addition, the use of the case method in teaching can reduce the likelihood of errors in practice to a minimum, as the main objective of medical education institutions is to help students gain knowledge at a level that will allow them to practise independently without making mistakes.

The analysis of the advantages and disadvantages of the case method compared to other modern methods that are introduced in learning, identified the following advantages: improved long-term memory, and increased quality of decisionmaking. The disadvantages include the difficulties related to implementing the method (Afsouran et al., 2018). In addition, the effectiveness of teaching using the case method can be influenced by the individual characteristics of students and teachers (Bayona \& Castañeda, 2017).

The aim of this study was to experimentally determine how case studies affect the mastering of practical skills and clinical experience in medical students. To achieve this aim, the following objectives had to be achieved:

1) To establish the impact of the case method on the development of practical skills and abilities of students of medical education institutions, and draw a conclusion about its effectiveness;

2) to determine the impact of the case method on the learning outcomes of students, comparing the final grades in the majors of the groups where the case method was used with those where it was not introduced;

3) to identify through a survey among students how, in their opinion, the case method affects their practical skills and clinical experience.

\section{Methods}

The study involved eleven teachers of five medical higher education institutions (HEIs) of Ukraine. The sample included two teachers from the Department of Dentistry of the Faculty of Postgraduate Education, Dnipropetrovsk Medical Academy of the Ministry of Health of Ukraine; two teachers from the Department of General Surgery and Postgraduate Surgical Education of Zaporizhzhia State Medical University and three teachers from Zhytomyr Medical Institute of the Zhytomyr Regional Council participated, as well as two teachers from Ajman University, College of Medicine, and two from the Ukrainian Medical Lyceum of Bogomolets National Medical University. The sample also included 117 students in their second to fourth years of study from the mentioned education institutions.

A data triangulation procedure was used in the study. Data collection was carried out through different methods, namely qualitative (observation, survey) and quantitative (comparison of the results of the final assessment of knowledge of students of the experimental and control groups) in order to increase the reliability of the obtained results.

The study was conducted in three phases. The first phase was a qualitative study, entailing the observation of students discussing clinical cases at the initial stage of introduction of the case method in teaching and throughout the period of the involvement with this method, as well as at the final stage of training. For the discussions, students used one of the largest case databases in the world, created 
by the European Clearing House (https:// www.thecasecentre.org/educators/casemethod/resources/freecasesov erview), as well as videos of real clinical situations.

The case method was introduced in the above-mentioned HEIs, adhering to the content and didactic goals of the subjects concerned, as well as the principles of the relevance of specific cases, and sufficient knowledge of students to complete the assignments.

The cases contained: 1) a set of videos of real (authentic) practical medical situations/cases; 2) instructions for students, and the study material required to be considered in a particular case; 3) schemas that allow tracking the relationship between the elements of the topics studied and the competencies that students should obtain when considering a particular case; 4) necessary reference tables and maps, diagrams; 5) educational literature; 6) collections of creative assignments and problems, as well as logical tasks; 7) multimedia video courses; 8 ) tests for self-assessment.

At the same time, the teacher guiding the students to a correct solution of the medical problem situation by asking simple questions in the course of the collective discussion of each practical case, used a pre-written scenario of student academic activities. According to the scenario, students had to solve a practical case independently during group discussions, as well as indicate all possible ways to solve it, with minimal teacher intervention.

The students' work on the cases was carried out in the following sequence:

1. Outlining the clinical case.

2. Self-preparation to accumulate the necessary theoretical material to solve the case situation.

3. Conducting a group discussion under the teacher's guidance.

4. Identifying options for solving a clinical case.

5. Analysis of potential results that may lead to the proposed actions.

6. Evaluation of actions.

In the study, observers evaluated:

1. The process of resolving a clinical situation (how the problem is identified, which of the case data are used, how the data are analysed, how the decision is made, whether it is unambiguous, whether the case may have several correct solutions).

2. Do students use previously acquired knowledge, professional language, terminology, analytical and decision-making skills, etc. during the discussion?

3. The nature of the discussion - the justification of solutions is based solely on theoretical knowledge, whether practical experience is used when a controversy occurs, whether the opinion of colleagues is supported, or questioned, and so forth.

4. How the communication takes place in the group during the discussion do students look for solutions independently, trust the opinion of classmates, or wait for the teacher's tips? 
The second phase of the study entailed the comparison of learning outcomes by comparing the final scores obtained by students during their final assessment in the same subjects in the same study year of two groups of students, one of which had used the case method, while the other group had not.

The third phase of the study consisted of an anonymous survey of students by means of the Waliany's technique (Waliany et al., 2019). Students who had not yet been taught by means of the case study method were asked to answer 14 questions that helped students assess the level of practical skills they had acquired while studying at an education institution. The students had to fill in the same questionnaire after the case study method had been introduced in their studies. The obtained statistical data were processed using the Statistica software package.

\section{Results}

During the first phase of the study, when the case method was used as a tool to assess the availability of practical skills and abilities of students, it was found that in all five medical education institutions involved in this study, the professionalism of the clinical case discussions differed, depending on the study year of students and their experience in using case studies. For example, secondyear students had not yet developed the ability to use medical terminology; their justifications were based on their theoretical knowledge in the relevant subjects available at the time of the study. In the second year, students spent a significant amount of time trying to understand the problem before starting to look for solutions. Sometimes the problem was misidentified, or they identified several problems in one situation. Conversely, students did not always indicate all possible solutions to the clinical situation. Future physicians often expected questions from the teacher who led the discussion in order to get clues to identify the appropriate solutions.

Third-year students showed more skilful use of professional terminology during the discussion. They quickly identified the problem. The clinical case was carefully evaluated and analysed. Sometimes the teacher's intervention was necessary to find the right options for solving the clinical situation. There was some interaction between students in the group during the discussion.

The fourth-year students had a proper level of professional language, and they correctly used medical terminology during the discussions. Coordinated teamwork was observed, and colleagues listened to each other's opinions. During the search for solutions, fourth-year students used both theoretical knowledge of relevant subjects and practical medical experience gained in-class in solving previous clinical situations. All possible clinical case solutions were developed and their consequences were assessed. The course of the discussion did not actually depend on the teacher.

Thus, senior students showed greater confidence in their knowledge and skills to apply them in solving specific medical cases during the discussion, which was based on a greater theoretical knowledge and more extended practical experience. The generalized results of observations are given in Figure 1. 


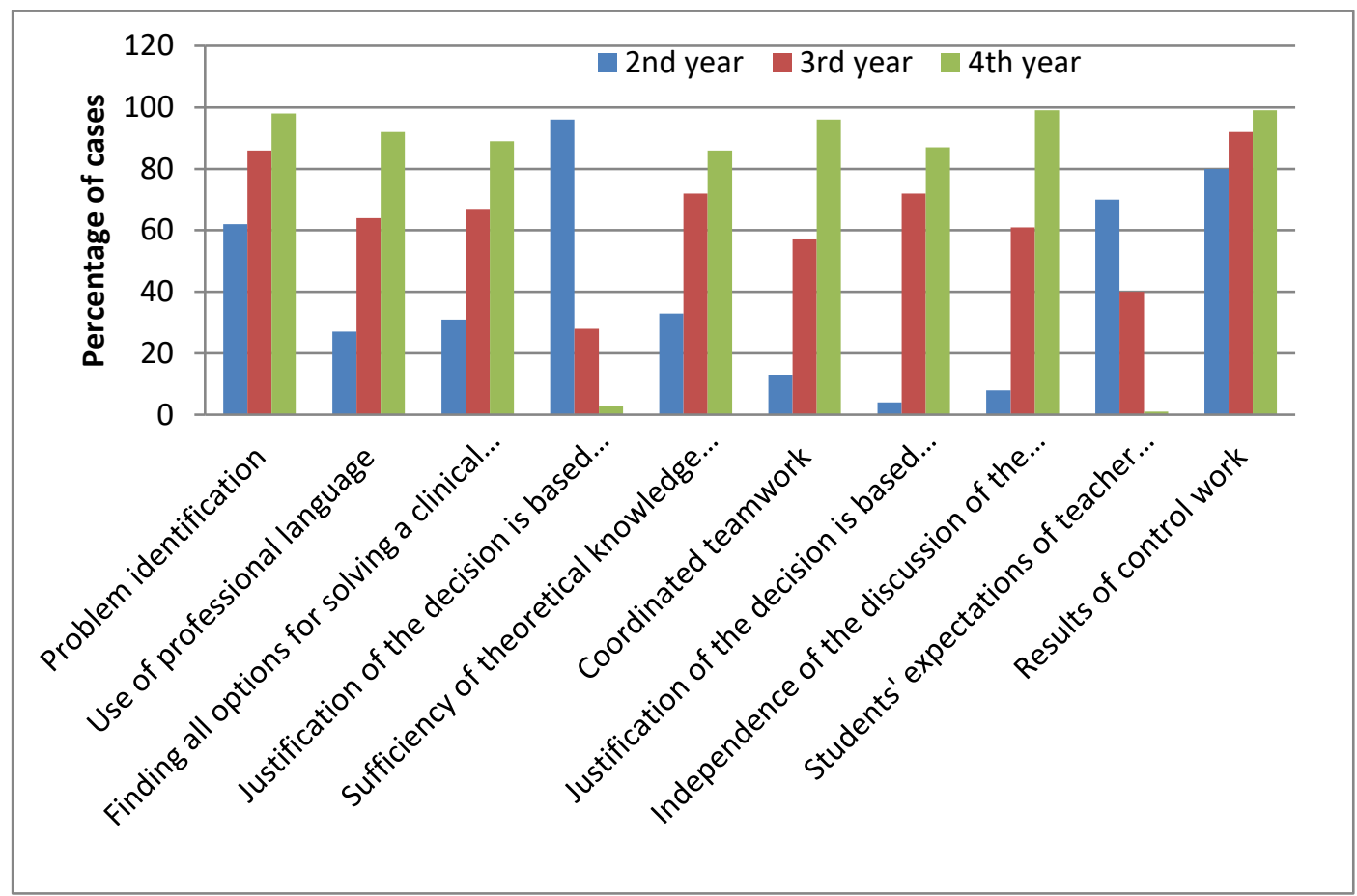

Figure 1: The results of using the case study method and gaining practical experience in solving clinical situations

Figures 2-4 demonstrate the dynamics of the acquisition of practical skills and abilities by medical students when using the methods of particular clinical cases in teaching.

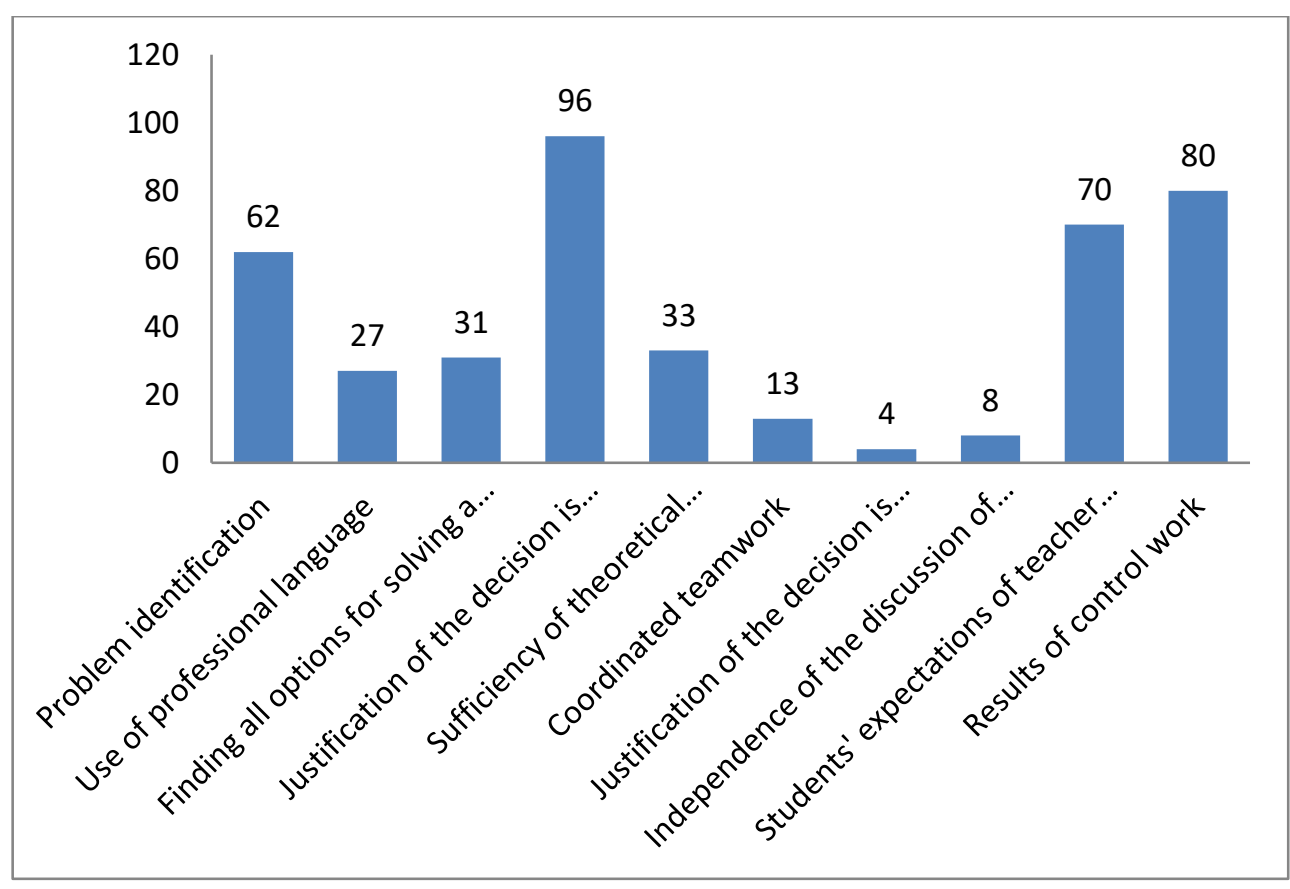

Figure 2: The results of using the case study method in the second year of study 


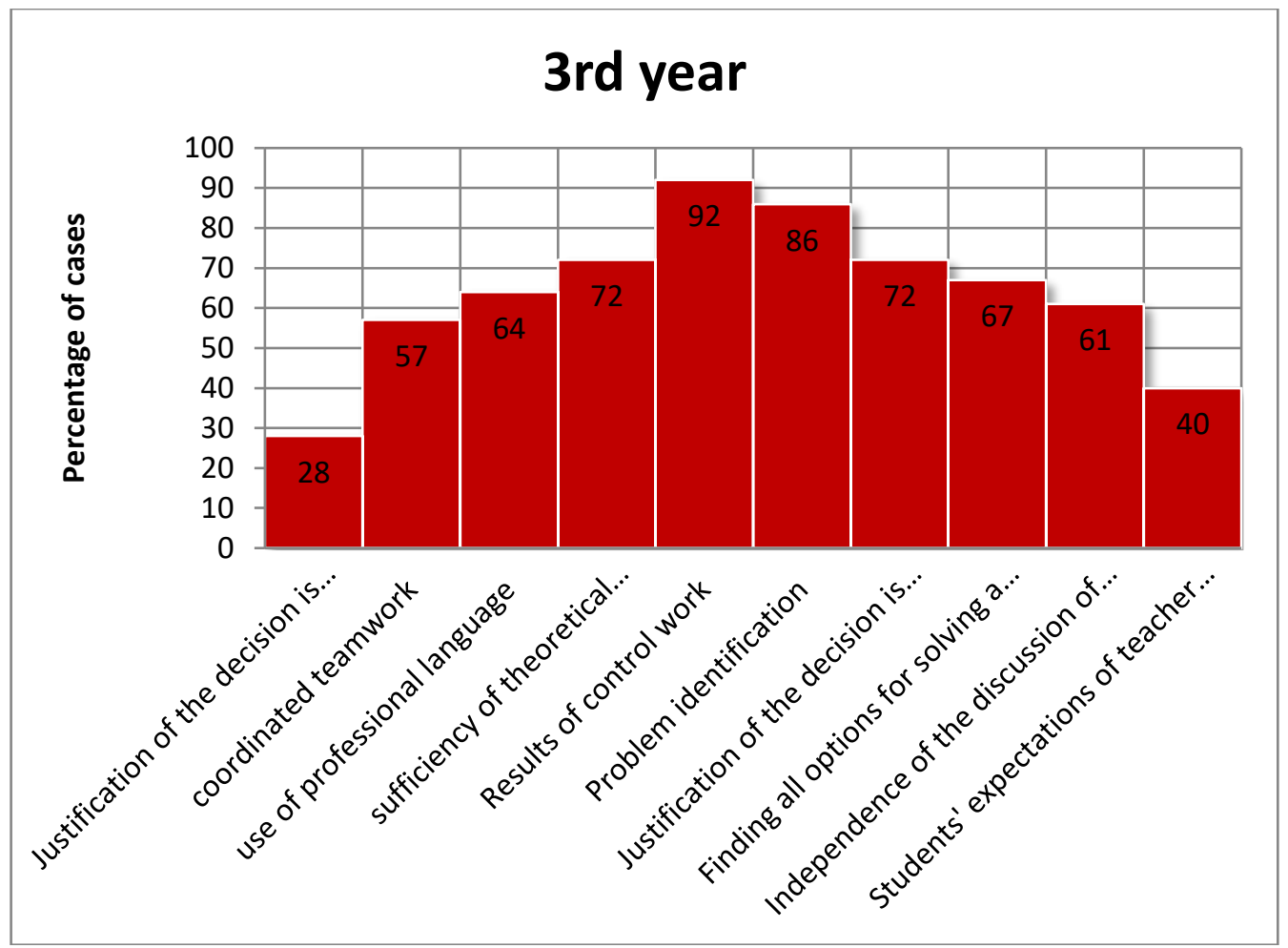

Figure 3: The results of using the case study method in the third year of study

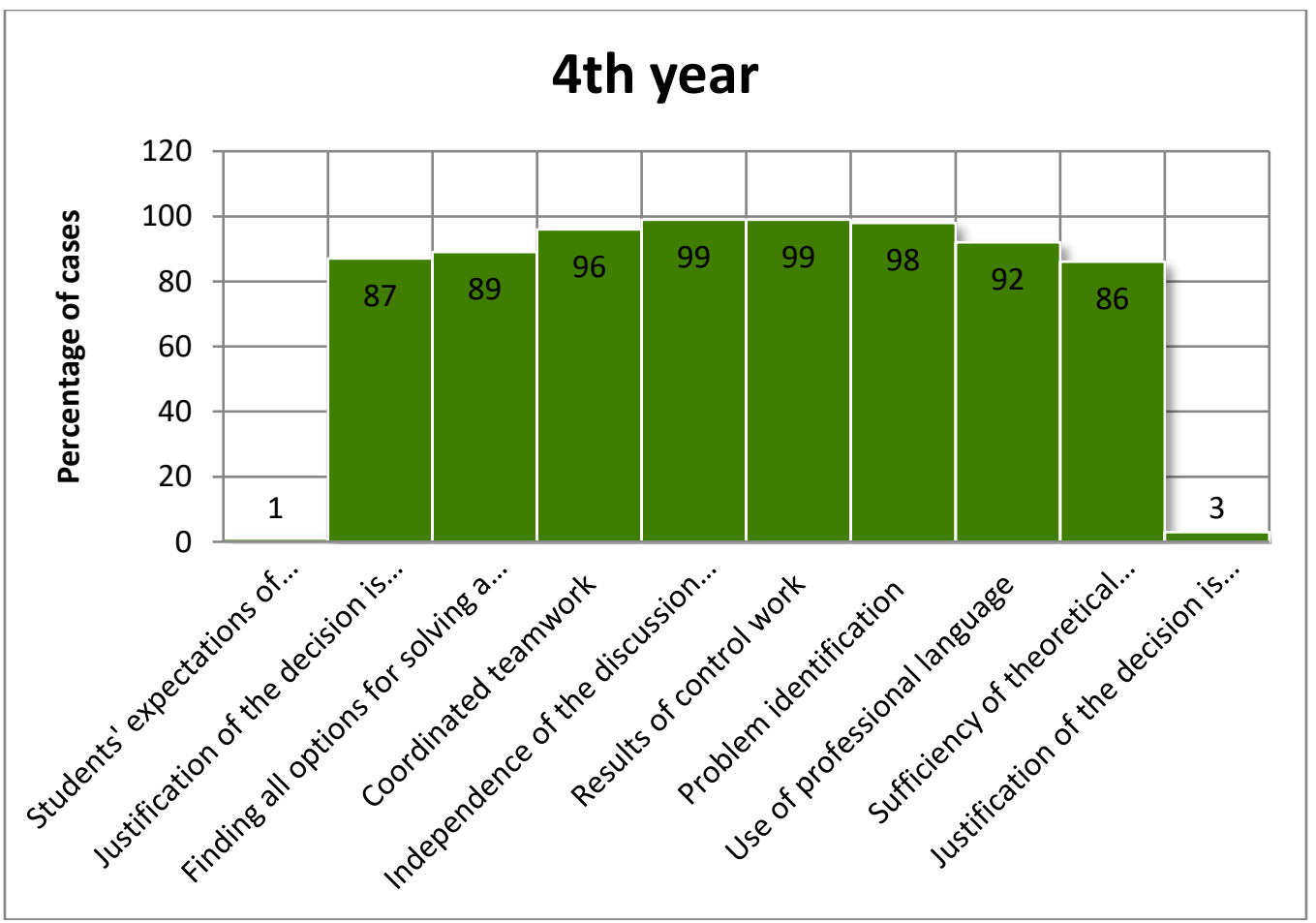

Figure 4: The results of using the case study method in the fourth year of study

As Figures 2-4 show, the distribution of criteria for assessing the practical skills and abilities required by future physicians, according to the percentage of 
observed cases, varied depending on the year of study. Thus, the observation revealed that the application of the method in particular situations in the training of future physicians improves the professional language of students, thereby increasing the speed and accuracy of problem identification, improves independence from the teacher in decision-making, coherence of teamwork, and the predominant use of clinical considerations in combination with theoretical knowledge.

In addition, a similar study was conducted during the first three years of the introduction of the case study method in teaching in the said medical HEIs among three groups of $4^{\text {th}}$-year students, where the case method had been used during the first year, and years two and three. There was a direct correlation between the term of application of the case-study and the degree of practical clinical experience of students obtained in-class.

The influence of the case method on student success was also investigated. Thus, comparing the average scores obtained by students during the final assessment of their knowledge in the subjects: Surgery and Prevention of Dental Diseases in the $2^{\text {nd }}, 3^{\text {rd }}$ and $4^{\text {th }}$ years of study in the said medical education institutions in groups where the case study method was introduced, and in groups in which other teaching methods were used. The scores obtained are shown in Figure 5.

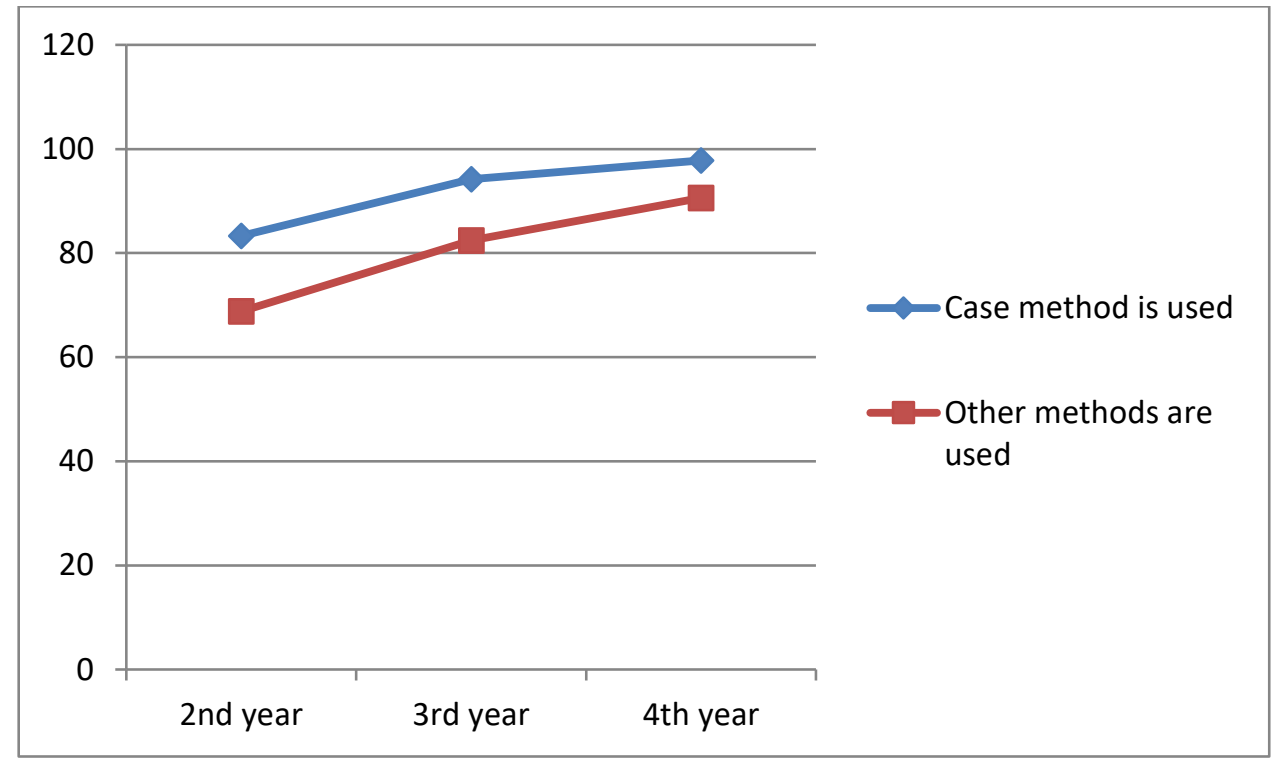

Figure 5: Average scores of students obtained during the final assessment of knowledge

As shown in Figure 5, student performance increased with the transition from one year of study to the next. For example, in the second year it was 68.8 , which is $22 \%$ less than in the fourth year of students in the groups where traditional methods were used in education. But performance is influenced more significantly by the teaching methods used. This study, based on the example of an interactive case study, showed that success can be increased by more than ten percent (about 29\%) when students actively interact with each other, looking for solutions to practical problems similar to those they will face in the future in the performance of their professional duties. 
It was found that the standard deviation from the mean score of the final assessment in different years of study was different. For example, in the second year, where teaching methods other than the case method were used, the standard deviation from the mean value of students' scores obtained during the final knowledge test was 305. Analysis of variance showed that variations in students' final grades are smaller when using the case study method. However, in the second year, where case study methods were used, the standard deviation from the mean value of students' scores obtained during the final knowledge test is still quite high and has a value of 162. As for fourth-year students, this figure is as follows: 161 in groups where other teaching methods were used, and 18 when the case method was used. In this case, the intergroup variance, which describes the fluctuations of these groups, and the intragroup variance, which describes the fluctuations of the data due to random factors not taken into account, are not equal, which indicates the invalidity of the null hypothesis. In the studies conducted in the second year in groups where the case study method was not used and where it was used, Cohen's d was 1.0, indicating a high effect size. In the third year, $d=0.8$, which indicates a great effect. In the fourth year, $d=0.5$, which corresponds with the average effect. That is, the effectiveness of the use of the case study method is a value that depends on the year of study and the experience of its application.

One of the components of the study was to examine the point of view of the students themselves on how the use of case study methods in the learning process affects their acquisition of professional skills and clinical experience in-class. For this purpose, an anonymous survey of students was conducted before the introduction of the case study method and after its use in the educational process. The revised and adapted Waliany's questionnaire (Waliany et al., 2019) was used for data collection.

Table 1 shows the results of questionnaires of second- and fourth-year students before and during the application of case study methods in teaching (the figures given in Table 1 are the percentage of positive answers to the questions), as well as the calculated values of Cohen's d.

Table 1: The results of student surveys on the impact of case study methods on the acquisition of practical clinical skills

\begin{tabular}{|c|c|c|c|c|c|c|c|}
\hline \multirow{2}{*}{ Skills } & \multirow{2}{*}{ Questions of the questionnaire } & \multicolumn{3}{|c|}{$2^{\text {nd }}$ year } & \multicolumn{3}{|c|}{$4^{\text {th }}$ year } \\
\hline & & d & before & after & d & before & after \\
\hline \multirow[b]{2}{*}{ 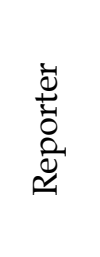 } & $\begin{array}{l}\text { I understand how to collect } \\
\text { information from patients }\end{array}$ & 1.17 & 63 & 81 & 0.92 & 85 & 99 \\
\hline & $\begin{array}{l}\text { I understand how to apply } \\
\text { physical examination } \\
\text { techniques, which aim to help } \\
\text { diagnose patients' problems }\end{array}$ & 1.37 & 45 & 66 & 0.98 & 82 & 97 \\
\hline \multirow{3}{*}{ 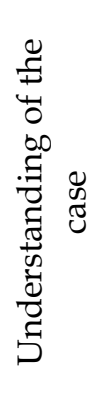 } & $\begin{array}{l}\text { I understand how doctors create } \\
\text { a list of problems that } \\
\text { correspond with a particular } \\
\text { clinical case }\end{array}$ & 1.5 & 41 & 65 & 0.33 & 85 & 90 \\
\hline & $\begin{array}{l}\text { I understand how doctors make } \\
\text { a differential diagnosis }\end{array}$ & 1.3 & 42 & 62 & 1.05 & 76 & 92 \\
\hline & $\begin{array}{l}\text { I understand how clinicians } \\
\text { interpret the results of diagnostic } \\
\text { tests }\end{array}$ & 1.7 & 12 & 38 & 1.57 & 64 & 88 \\
\hline
\end{tabular}

http://ijlter.org/index.php/ijlter 


\begin{tabular}{|c|c|c|c|c|c|c|c|}
\hline & $\begin{array}{l}\text { I understand how to apply } \\
\text { clinical information obtained } \\
\text { before diagnosing patients }\end{array}$ & 1.77 & 37 & 64 & 1.05 & 71 & 87 \\
\hline \multirow{3}{*}{ 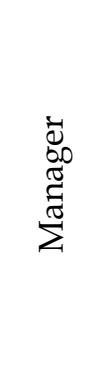 } & $\begin{array}{l}\text { I understand how doctors } \\
\text { determine the necessary } \\
\text { diagnostic tests }\end{array}$ & 1.76 & 15 & 42 & 1.89 & 66 & 95 \\
\hline & $\begin{array}{l}\text { I understand how clinicians } \\
\text { choose treatment options for } \\
\text { their patients }\end{array}$ & 1.57 & 39 & 63 & 1.24 & 70 & 89 \\
\hline & $\begin{array}{l}\text { I know how doctors manage } \\
\text { patient care }\end{array}$ & 1.17 & 60 & 78 & 0.78 & 85 & 97 \\
\hline $\begin{array}{l}\text { Tea- } \\
\text { cher }\end{array}$ & $\begin{array}{l}\text { I understand how to share } \\
\text { information with my patients }\end{array}$ & 1.17 & 62 & 80 & 0.98 & 84 & 99 \\
\hline \multirow{4}{*}{ 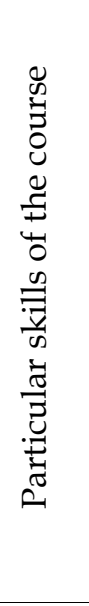 } & $\begin{array}{l}\text { I know how physicians work } \\
\text { step by step on a clinical case in } \\
\text { establishing primary patient care }\end{array}$ & 1.37 & 42 & 63 & 0.98 & 79 & 94 \\
\hline & $\begin{array}{l}\text { I understand every step that } \\
\text { doctors take in resolving a } \\
\text { specific clinical situation and } \\
\text { making a diagnosis. }\end{array}$ & 1.76 & 29 & 56 & 1.5 & 68 & 91 \\
\hline & $\begin{array}{l}\text { I understand the step-by-step } \\
\text { clinical process of doctors' work }\end{array}$ & 1.17 & 60 & 78 & 1.17 & 78 & 96 \\
\hline & $\begin{array}{l}\text { I follow the current problems } \\
\text { faced by medicine, and study the } \\
\text { proposed ways to overcome } \\
\text { them }\end{array}$ & 0.85 & 64 & 77 & 0.98 & 75 & 90 \\
\hline
\end{tabular}

As Table 1 shows, according to students, after applying the case study method, they became more confident in their practical capabilities, namely they gained experience in collecting information from the patient needed to plan an examination and treatment, learned to organize and manage patient care, learned to share information with a patient, reached an understanding of the details of the initial treatment and diagnosis. The greatest effect of the use of the case study was observed in the assessment of the impact of the case study method on the development of skills in second-year students to determine the necessary tests for diagnosis and interpret their results. The impact of this method also is clearly observable in fourth-year students' development of step-by-step algorithms for clinical cases when establishing primary care needs of the patient and making a diagnosis.

The study showed that the case study method helped to increase students' interest in the new challenges facing medicine and ways to overcome difficulties in the global medical community. Comparing Cohen's d for different years of study, we can conclude that the use of the case-study method in the second year is more effective than in the fourth year. For example, the answers to the question "I understand how to apply the methods of physical examination, which aim to help diagnose the problems of patients" received $d=1.37$ in the second year, and $d=$ 0.98 in the fourth year. The degree of the effect also differs among the students, according to the questionnaire responses. It was found that for twelve of the 
fourteen cases, the effect of the case-study method was higher in the second year than in the fourth. Compared to the results obtained from studies on the impact of case study methods on the final grades obtained by students in subjects that were taught by means of other teaching methods and the case study method, we found the same trend in method effectiveness: higher efficiency of the method in the second year, slightly lower in the third year, and the fourth year was shown to render the lowest method effectiveness. This suggests that it is necessary to apply case study methods starting from the first year of study, which will give the maximum possible positive effect in the acquisition of practical clinical skills and abilities of students.

\section{Discussion}

According to the classification of learning models by Joyce and Weil (1972), the case method performs functions similar to several learning models simultaneously. In particular, the Inductive Model (Hilda Taba) and the Concept Attainment (Jerome Bruner) promote the development of inductive academic reasoning and the construction of theories based on specific examples. The Advance Organisers' Model (David Ausubel) helps to increase the efficiency of information processing, and the application of acquired knowledge in solving practical problems. Group Investigation (Herbert Thelon, John Dewey) and Social Inquiry (Byron Massialas, Benjamin Cox) develop the skills of democratic interaction between an individual and a group of individuals during academic research. Non-Directive Teaching (Carl Rogers) promotes the development of learning independence and, as a consequence, the development of selfunderstanding, self-discovery and self-recognition. The Classroom Meeting Model (William Glasser), in addition to self-understanding, stimulates the development of self-responsibility (Joyce \& Weil, 1972). However, there is a discrepancy between the case method and similar but significantly different methods, such as problem-based and team-based learning (Donkin et al., 2021).

The use of the case method has become even more appropriate and even an undeniable necessity during the 2020 pandemic. The forced transition to distance learning has become a challenge for medical institutions, which have to provide not only theoretical knowledge to future physicians, but also the practical skills needed for clinical practice (Wong, 2020). Very soon the case method was transformed into the online case method (Donkin et al., 2021).

During the pandemic, for example, in Canada, all classes (lectures, discussions, case studies) in medical education institutions were replaced by distance learning classes using Internet platforms. Under such conditions, classes using case methods were converted into video conferences (Wong, 2020). Medical schools in Pakistan also used cases in remote training (Mukhtar et al., 2020).

According to the research, in cases of distance learning the average score for subjects in which the case method was used increased by $48 \%$ compared to the scores of students who studied using other methods (Manalo et al., 2021). Research reports also confirm the positive impact of the use of case studies, coordinated remotely by clinicians, on the training of medical students and their learning outcomes (Suneja et al., 2020), and on the teaching of nursing students 
(Liang et al., 2020). According to Atwa et al. (2019), it was found in a study they conducted that $44 \%$ of students demonstrated improved performance through the use of a hybrid learning model that combined team learning and the use of case studies.

The research reported here was the first comprehensive experimental study in the Ukraine aimed at establishing the impact of the case study method on the effectiveness of medical students' practical skills. The study covered five medical HEIs. It was based on observation, and a comparison of the results of the final assessment of knowledge and skills. The study involved a survey of 117 students in three different years of study, who had considered more than 80 different clinical situations over three years. The study results showed a high level of effectiveness of the case method in the acquisition of practical skills and abilities of students ( $d>1$ in the vast majority of cases).

Using the case method as a research tool in this study, we confirmed the following: The application of the case method leads to the transition of students from reasoning that operates only on theoretical knowledge, to clinical reasoning based on their own experience (also see Orban et al., 2017). The results also showed that the use of the case method has the highest effect when it is introduced in the second year of medical education, in contrast to the introduction in the fourth year. This is evidenced by the obtained Cohen coefficients: $d=1.0$ in the second year and $d=0.5$ in the fourth year. This finding confirms that a good incentive for students of medical schools to acquire professional skills is the use of cases from the first days of study (Servant-Miklos, 2019). Acquainting students with the problems of patients from their first year of study allows them to understand the difference between their capabilities and the needs of patients. It also demonstrates the relevance of educational material and knowledge required in future to perform professional duties, and encourages the acquisition of the necessary knowledge, skills and abilities.

The survey conducted among medical students in this study confirmed that the best results of the use of the case method are achieved in the second study year. However, fourth-year students also reported that case studies had a positive effect on students' clinical experience during their studies.

Other surveys in HEIs in the Ukraine, included surveys among medical students. In particular, an anonymous survey was conducted with 41 students majoring in Paediatrics and Children's Infectious Diseases at the Higher State Education Institution, the Bukovynian State Medical University. This survey showed that the use of case-based teaching methods in medical HEIs can reduce the number of medical errors that may lead to death. The Department of Pedagogy and Psychology, Postgraduate Education of the Bogomolets National Medical University also uses the case study method. They consider it a synthesis of three methods, namely role play, discussion, and specific situations, and it is widely used to shape students' clinical thinking (Kyrychok, 2016). Teachers of the Ukrainian Medical Dental Academy also regard it as a positive experience to use case study teaching methods along with other innovative technologies. In particular, it is effectively used at the Department of Internal Medicine during 
practical classes in the 4th and 6th years, at clinical and pathoanatomical conferences, and during internships (Skrypnyk et al., 2012).

The case study method can be used in the development of professional and business communication, as shown by the example of the Medical College of Ukrainian Medical Dental Academy, Poltava (Bondar, 2018). It can also be used in teaching specialized subjects, as shown by teachers of the Department of Hospital Paediatrics of Zaporizhzhia State Medical University (Lezhenko et al., 2016). Kharkiv National Medical University is working at creating a general university database of clinical cases (Lopina \& Zhuravlyova, 2018). Sechenov First Moscow State Medical University conducted studies in 2012-2013 at the Faculty of Pharmacy. These studies showed an increased rate of assimilation of educational material by students using case study methods, reduced number of errors in solving professional practical problems, and increased motivation to learn (Litvinova et al., 2017). In a study involving 170 students from Stanford School (Waliany et al., 2019), the experimental group was trained according to a specially designed programme with case studies. Results showed that the experimental group was more effective in diagnosing patients than control groups that followed the usual programmes. These examples are evidence of case studies having become a prerequisite for the education of competitive physicians.

The features of the use of the case study method in medical education have been studied, and the advantages and disadvantages of its use have been analysed (Kyrychok, 2016). It was established that when considering specific cases, it is important to take into account the effect of the way in which information about the case is conveyed to or collected by the students, as this may influence the results of its application. It was found that the students who received information about a clinical case from live communication with the patient had the best learning outcomes. Students who received information from a video fared less well, while the least effective method of information transfer is through paper documents (Weidenbusch et al., 2019).

At the same time, a good incentive for acquiring professional skills for students of medical education institutions is the use of cases from the first days of study in medical school (Servant-Miklos, 2019). Familiarization of students with the problems of patients from their first year of study allows them to understand the difference between their capabilities and the needs of patients, demonstrates the relevance of educational material and knowledge needed in the future to perform professional duties, and encourages the acquisition of the required knowledge, skills and abilities.

\section{Conclusion}

The issue of finding and introducing methods that will provide medical students with not only a theoretical background but also practical clinical experience over the years of study is topical because of the need of the world's population for qualified physicians. One way to achieve this is through case studies. This study proved the usefulness of using case studies to improve students' practical skills, and, in particular, to identify clinical cases, plan examinations, examine patients, interact with patients and colleagues, diagnose, plan treatment and make 
predictions. The case study method promotes the acquisition of theoretical knowledge, as was revealed in the final assessment. The positive impact of using clinical cases on attaining learning outcomes was proven, and a survey of medical students showed that the case method helped students master the practical skills they need to perform their professional duties. The results of this study will be useful for educators who are looking for effective teaching methods aimed at supporting students to gain practical experience during their study years, as well as for scholars who study the impact of interactive teaching methods on the acquisition of competencies by medical students. A need exists to create a national database of case studies that contains a sufficient number of clinical situations and covers the maximum topics and subjects in order to ensure that teachers do no compose case studies by themselves, because this difficult process may ensue in them choosing other, less effective, teaching methods.

\section{References}

Afsouran, N. R., Charkhabi, M., Siadat, S. A., Hoveida, R., Oreyzi, H. R., \& Thornton III, G. C. (2018). Case-method teaching: Advantages and disadvantages in organizational training. Journal of Management Development, 37, 711-720. https://doi.org/10.1108/JMD-10-2017-0324

Ali, M., Han, S. C., Bilal, H. S. M., Lee, S., Kang, M. J. Y., Kang, B. H., Razzaq, M. A., \& Amin, M. B. (2018). iCBLS: An interactive case-based learning system for medical education. International Journal of Medical Informatics, 109, 55-69. https:// doi.org/10.1016/j.ijmedinf.2017.11.004

Atwa, S., Gauci-Mansour, V. J., Thomson, R., \& Hegazi, I. (2019). Team-based and casebased learning: A hybrid pedagogy model enhancing students' academic performance and experiences at first-year tertiary level. The Australian Educational Researcher, 46(1), 93-112. https:/ / doi.org/10.1007/s13384-018-0282-y

Bayona, J. A., \& Castañeda, D. I. (2017). Influence of personality and motivation on case method teaching. The International Journal of Management Education, 15(3), 409-428. https:// doi.org/10.1016/j.ijme.2017.07.002

Bondar, N. V. (2018). Application of case-study in language classes in medical schools. In I. Y. Hubenko, O. T. Shevchenko, P. O. Hayday \& V. D. Konoba (Eds), AllUkrainian scientific and methodical Internet conference dedicated to the founding day of the educational institution "Cherkasy Medical Academy" (pp. 28-31). Cherkasy Medical Academy.

Chamala, S., Maness, H. T., Brown, L., Adams, C. B., Lamba, J. K., \& Cogle, C. R. (2021). Building a precision oncology workforce by multidisciplinary and case-based learning. BMC Medical Education, 21, Art. 75. https://doi.org/10.1186/s12909021-02500-6

Donkin, R., Yule, H., \& Fyfe, T. (2021). Application of online case-based learning in pre-clinical medical education: A scoping review protocol. Australia: University of the Sunshine Coast.

Edenhammar, C. (2017). The dynamics of the case method: A comparative study. Diva Portal. https://www.diva-portal.org/smash/get/diva2:1064011/FULLTEXT01.pdf

Eid, A., \& Quinn, D. (2017). Factors predicting training transfer in health professionals participating in quality improvement educational interventions. BMC Medical Education, 17, Art. 26. https://doi.org/10.1186/s12909-017-0866-7

Gartmeier, M., Pfurtscheller, T., Hapfelmeier, A., Grünewald, M., Häusler, J., Seidel, T., \& Berberat, P. O. (2019). Teacher questions and student responses in case-based 
learning: Outcomes of a video study in medical education. BMC Medical Education, 19, Art. 455. https:// doi.org/10.1186/s12909-019-1895-1

Harrison, H., Birks, M., Franklin, R., \& Mills, J. (2017). Case study research: Foundations and methodological orientations. Forum: Qualitative Social Research, 18(1), Art. 19 January. https:// doi.org/10.17169/fqs-18.1.2655

Joyce, B. \& Weil, M. (1972). Conceptual Complexity, Teaching Style and Models of Teaching. National Council for the Social Studies. https://digitalcommons.georgiasouthern.edu/ct2-library/96

Kyrychok, V. A. (2016). Possibilities of application of interactive teaching methods in the system of postgraduate medical education. Medical Education, 1, 25-28.

Lezhenko, G. O., Hyria, O. M., Pashkova, E. E., Gladun, K. V., Lebedynets, O. M., \& Yartseva, M. O. (2016). The use of the case method in teaching $5^{\text {th }}$-year medical students at the department of hospital paediatrics. In G. O. Lezhenko (Ed.), Higher medical education: Modern challenges and prospects. Abstracts of scientific-practical conference with international participation, March 3-4, 2016, Kyiv (pp. 307-308). KIM.

Liang, Y. J., Wei-Ju, C., Shuang, Z., Lin, W., Qiu-Ying, L., Wan-Xian, L., \& Chen-Li, L. (2020). An innovative approach of using online problem-based learning and case-based learning in teaching disaster nursing during the COVID-19 pandemic. Journal of Integrative Nursing, 2(4), 196-202. https://doi.org/10.4103/jin.jin_44_20

Likhachov, V. K., Shimanska, Y. V., Taranovska, O. O., Dobrovolska, L. M. \& Makarov, O. H. (2019). Case technologies as a productive means of forming competency professional skills at the stage of postgraduate medical education. Ukrainian Medical and Dental Academy.

http://elib.umsa.edu.ua/jspui/bitstream/umsa/10025/1/Likhachov_Keis_tek hnolohii_iak_produktyvnyi_zasib.pdf.

Litvinova, T. M., Glazkova, I. Y., Kolomiets, O. M., Smyslova, O. A., \& Denisova, M. N. (2017). Using case method in organizing student academic/professional activity as part of the educational process. Espacios, 38(56), 291-305.

Lopina, N., \& Zhuravlyova, L. (2018). Practice-oriented case-method of teaching in the system of continuing medical education based on information web technologies. Collection of Scientific Works of Borys Grinchenko Kyiv University and the Anton Makarenko Charitable Foundation "Continuous Professional Education: Theory and Practice ", 3-4, 67-73.

Manalo, T. A., Higgins, M. I., Pettitt-Schieber, B., Pettitt, B. J., Mehta, A., \& Hartsell, L. M. (2021). A strategy for undergraduate medical education in urology during the COVID-19 pandemic. Journal of Surgical Education, 78(3), 746-750. https:// doi.org/10.1016/j.jsurg.2020.09.011

McLean, S. F. (2016). Case-based learning and its application in medical and health-care fields: A review of worldwide literature. Journal of Medical Education and Curricular Development, 3, 39-49. https://doi.org/10.4137/JMECD.S20377

Mukhtar, K., Javed, K., Arooj, M., \& Sethi, A. (2020). Advantages, limitations and recommendations for online learning during COVID-19 pandemic era. Pakistan Journal of Medical Sciences, 36 (COVID19-S4), S27-S31. https://doi.org/10.12669/pjms.36.COVID19-S4.2785

Napryeyenko, O., Napryeyenko, N., Marazziti, D., Loganovsky, K., Mucci, F., Loganovskaja, T., \& Tsekhmister, Y. (2019). Depressive syndromes associated with alcohol dependence. Clinical Neuropsychiatry, 16(5-6), 174-180. http://doi.org/10.36131/clinicalnpsych2019050603

Orban, K., Ekelin, M., Edgren, G., Sandgren, O., Hovbrandt, P., \& Persson, E. K. (2017). Monitoring progression of clinical reasoning skills during health sciences 
education using the case method: A qualitative observational study. BMC Medical Education, 17, Art. 158. https://doi.org/10.1186/s12909-017-1002-4

Pavlyshyn, H. A, Bihuniak, T. V., \& Savaryn, T. V. (2015). Case method of teaching in medical education. Medical Education, 3, 67-69.

Sandelowsky, H., Krakau, I., Modin, S., Ställberg, B., Johansson, S. E. \& Nager, A. (2018). Effectiveness of traditional lectures and case methods in Swedish general practitioners' continuing medical education about COPD: A cluster randomised controlled trial. BMJ Open, 8(8), e021982. https:/ / doi.org/10.1136/bmjopen-2018021982

Sayre, J. W., Toklu, H. Z., Ye, F., Mazza, J., \& Yale, S. (2017). Case reports, case series: From clinical practice to evidence-based medicine in graduate medical education. Cureus, 9(8), e1546. https://doi.org/10.7759/cureus.1546

Servant-Miklos, V. F. (2019). The Harvard connection: How the case method spawned problem-based learning at McMaster University. Health Professions Education, 5(3), 163-171.https://doi.org/10.1016/j.hpe.2018.07.004

Skrypnyk, I. M., Sorokina, S. I., Shevchenko, T. I., Kudrya, I. P., \& Shaposhnyk, O. A. (2012). Case method as an example of interactive teaching of medical students to clinical disciplines. Chelpanov' Psychological and Pedagogical Reading, 1(2012), 372377.

Suneja, S., Gangopadhyay, S., \& Kaur, C. (2020). Efforts to cope with CBME in COVID-19 era to teach biochemistry in medical college. Biochemistry and Molecular Biology Education, 48(6), 670-674. http://doi.org/10.1002/bmb.21469

Tsekhmister, I. V., Daniliuk, I. V., Rodina, N. V., Biron, B. V., \& Semeniuk, N. S. (2019). Developing a stress reaction inventory for eye care workers. Oftalmologicheskii Zhurnal, 1, 39-45. http://doi.org/10.31288/oftalmolzh201913945

Turk, B., Ertl, S., Wong, G., Wadowski, P. P., \& Löffler-Stastka, H. (2019). Does case-based blended-learning expedite the transfer of declarative knowledge to procedural knowledge in practice? BMC Medical Education, 19, Art 447. https:// doi.org/10.1186/s12909-019-1884-4

Vasylieva, N. (2020). Lecturing in clinical medical education. Sciences of Europe, 52(4), 52.

Waliany, S., Caceres, W., Merrell, S. B., Thadaney, S., Johnstone, N., \& Osterberg, L. (2019). Preclinical curriculum of prospective case-based teaching with faculty-and student-blinded approach. BMC Medical Education, 19, Art. 31. https://doi.org/10.1186/s12909-019-1453-x

Wei, F., Sun, Q., Qin, Z., Zhuang, H., Jiang, G., \& Wu, X. (2021). Application and practice of a step-by-step method combined with case-based learning in Chinese otoendoscopy education. BMC Medical Education, 21, Art. 89. https:// doi.org/10.1186/s12909-021-02513-1

Weidenbusch, M., Lenzer, B., Sailer, M., Strobel, C., Kunisch, R., Kiesewetter, J., Fischer, M. R., \& Zottmann, J. M. (2019). Can clinical case discussions foster clinical reasoning skills in undergraduate medical education? A randomised controlled trial. BMJ Open, 9(9), e025973. https:// doi.org/10.1136/bmjopen-2018-025973

Wong, R. Y. (2020). Medical education during COVID-19: Lessons from a pandemic. British Columbia Medical Journal, 62(5), 170-171.

Zakaliuzhnyi, V. M. (2019). Case method and its application in the process of teaching physics. Scientific Bulletin of the Kyiv Pedagogical Drahomanov University, Series 5, $77,65-80$.

Zarnadze, S., Zarnadze, I., Baramidze, L., Sikharulidze, Z., Tabidze, D., \& Bakradze, T. (2018). Problem-based and case-study methodology in medical education. European Scientific Journal, 14(August Special), 120-128. https://doi.org/10.19044/esj.2018.c5p9 